\title{
The World Journal of Surgery Welcomes Dr. Adnan Alseidi to the Editorial Board
}

\author{
Julie Ann Sosa ${ }^{1}$
}

Dr. Adnan Alseidi is Professor of Clinical Surgery and Vice Chair for Education in the Department of Surgery at UCSF. Dr. Alseidi completed his Medical degree at the Pennsylvania State University Medical School followed by General Surgery residency at the University of Illinois at Chicago. Following graduation from residency, he served as a surgeon in the US Navy where he was the Co-Director of General Surgery for the US Naval Hospital Okinawa. Upon separation from the US Navy, he completed an HPB and Advanced GI fellowship at Washington University in St. Louis, MO, and earned a master's degree in surgical education at Southern Illinois University/University of Illinois-UC. He currently is the Chair for Education and Training for the Americas Hepato-Pancreato-Biliary Association, the chair for HPB for The Society of American Gastrointestinal and Endoscopic Surgeons, and the President-elect for the Association of Surgical Education.

Julie Ann Sosa, MD, MA, FACS—Editor in Chief, World Journal of Surgery.

Julie Ann Sosa

julie.sosa@ucsf.edu

1 University of California San Francisco (UCSF),

San Francisco, CA, USA

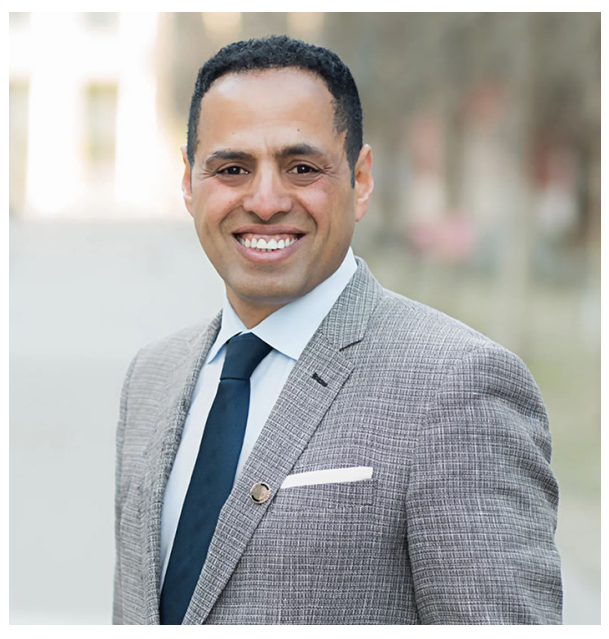

Publisher's Note Springer Nature remains neutral with regard to jurisdictional claims in published maps and institutional affiliations. 